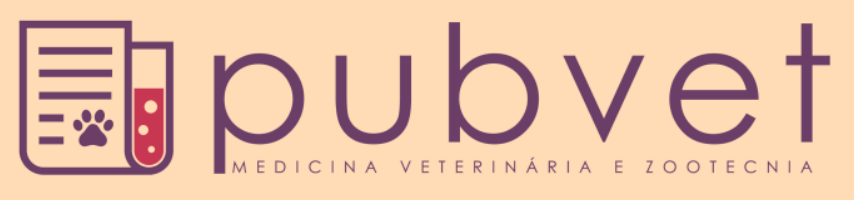

https://doi.org/10.22256/pubvet.v12n3a50.1-4

\title{
Insuficiência cardíaca associada à histiocitose linfoide com eritropoiese extramedular no baço: Relato de caso
}

\author{
Samuel Otemi de Sousa Silva ${ }^{\bullet}$, Raquel Albuquerque Silva ${ }^{\bullet}{ }^{2}$, Aline Silva Santos ${ }^{\bullet}$, \\ Daniele Benigno Mota ${ }^{1}$, Duan Kessiley Torres de Sousa 1 \\ ${ }^{1}$ Graduando do Curso de Medicina Veterinária, Centro de Ciências Agrárias, Universidade Federal do Piauí, Brasil \\ ${ }^{2}$ Residente do Hospital Veterinário Universitário da Universidade Federal do Piauí, Brasil \\ *Autor para correspondência, samuelotemi@gmail.com
}

\begin{abstract}
RESUMO. O presente relato relaciona a insuficiência cardíaca e as alterações inflamatórias sistêmicas ao descrever um caso clínico de um paciente canino macho com insuficiência cardíaca e histiocitose linfoide com eritropoiese extramedular no baço. $\mathrm{O}$ paciente apresentou aumento generalizado das câmaras cardíacas com disfunção em ambos os ventrículos e baço aumentado com presença de nódulos disseminado por todo o parênquima. Foi realizado a esplenectomia feito biópsia deste baço, chegando ao diagnóstico por citologia. A insuficiência cardíaca causa alterações inflamatórias sistêmicas, esta correlação com patologias relacionada a estimulo imunológico persistente ainda não foi estudado. A cirurgia realizada e o tratamento contínuo para insuficiência cardíaca restabeleceu a saúde do animal.
\end{abstract}

Palavras chaves: Insuficiência cardíaca, inflamatórias, esplenectomia

\section{Heart Failure Associated with Lymphoid Histiocytosis with Extramedullary Erythropoiesis in the Spleen: Case Report}

\begin{abstract}
The present report relates to heart failure and systemic inflammatory changes when describing a clinical case of a male canine patient with heart failure and lymphoid histiocytosis with extramedullary erythropoiesis in the spleen. The patient presented a generalized increase of cardiac chambers with dysfunction in both ventricles and enlarged spleen with presence of nodules spread throughout the parenchyma. Splenectomy was performed by biopsy of this spleen, arriving at the diagnosis by cytology. Heart failure causes systemic inflammatory changes, this correlation with pathologies related to persistent immune stimulation has not yet been studied. Surgery performed and continued treatment for heart failure restored the animal's health.
\end{abstract}

Keyswords: Heart failure, inflammatory, splenectomy

\section{Insuficiencia cardíaca asociada a la histiocitosis linfoide eritropoyesis extramedular en el bazo: Reporte de un caso}

RESUMEN. El presente relato relaciona la insuficiencia cardíaca y las alteraciones inflamatorias sistémicas al describir un caso clínico de un paciente canino macho con insuficiencia cardíaca e histiocitosis linfoide con eritropoyesis extramedular en el bazo. El paciente presentó un aumento generalizado de las cámaras cardíacas con disfunción en ambos ventrículos y bazo aumentado con presencia de nódulos diseminados por todo el parénquima. Se realizó la esplenectomía con biopsia de este bazo, llegando al diagnóstico por citología. La insuficiencia cardíaca causa alteraciones inflamatorias sistémicas, esta 
correlación con patologías relacionada con el estímulo inmunológico persistente aún no ha sido estudiado. La cirugía realizada y el tratamiento continuo para insuficiencia cardiaca restablecieron la salud del animal.

Palabras clave: Insuficiencia cardíaca, inflamación, esplenectomía

\section{Introdução}

A insuficiência cardíaca tem como patogênese a hiperextensão dos cardomiócitos que causa liberação de citocinas pró-inflamatórias na corrente sanguínea como TNF alfa, a IL1 e a IL6. Estas substâncias têm a capacidade de amplificar a resposta imune e atua na mobilização e agregação de neutrófilos e células polimórficas nucleares (Mann, 2002) e causam lesão tóxica nos cardiomiocitos devido à formação de radicais livres (Torre-Amione et al., 1996).

A resposta inflamatória constante atua na formação da síndrome inflamatória sistêmica com expressão acentuada da resposta imune. A histiocitose com eritropoiese medular está relacionada ao estimulo imune constante, e ao aumento da atividade fagocitária que é comum em parasitoses como a leishmania, destruição dos eritrócitos por IGg e recrutamento de células polimorfonucleares com eritropoiese extra medular (Tobias \& Johnston, 2013).

O presente relato de caso contém relevância clinica devido a poucos estudos relacionarem insuficiência cárdica com alterações sistêmicas e com alterações patológicas no baço. Esta correlação entre alterações cardíacas e a síndrome inflamatória sistêmica com liberação de TNF $\alpha$ e citocinas pró-inflamatórias é muito pouco estudada em medicina veterinária. Este relato contribui para clínicos que realizaram futuros diagnósticos em casos que associa insuficiências cardíacas com doenças correlacionadas ao estímulo imune persistente e a síndrome inflamatória sistêmica.

Segundo Torre-Amione (2005) a produção miocárdica do TNF-alfa justifica o aumento das citocinas, onde a distensão parietal diastólica ocasiona a superexpressão local de TNF - alfa, e as citocinas extravasa para a circulação, contribuindo para a ativação imune e o estado de inflamação sistêmica (SRIS). O desencadeamento da SRIS, a presença de TNF alfa é considerada o principal mediador químico da resposta inflamatória aguda e a única citocina capaz de induzir de maneira isolada a SIRS (Torre-Amione, 2005). Uma característica marcante e invariável da SRIS consiste na indução e liberação de citocinas e proteínas de fase aguda, tanto pró- inflamatórias quanto anti-inflamatórias. Elevando os valores séricos proteicos durante a resposta sistêmica (Salles et al., 1999, Brito, 2007). Normalmente alteração no baço é comum em animais idosos pela diminuição natural da imunidade decorrente da senilidade e pela diminuição de produção hormonal estes possui efeito de proteção epitelial como o GH (Harrison, 1990).

O estimulo imune constante causa aumento de agregados linfoides ao longo das arteríolas, os linfócitos se tornam imunoblastos e em um segundo estagio um centro germinativo ativo é percebido misturado a células plasmáticas. $\mathrm{O}$ folículo linfoide germinativo sofre reação folicular hiperplásica, apresentando padrão estrelado devido à presença de macrófagos (histiócitos). O sistema imune atinge o máximo de atividade e começa a declinar, com aumento de depósitos hialinos e aumento epitelial de hostiócitos (Bergman \& Heidger, 2001).

$\mathrm{O}$ aumento no volume do baço pode levar a um deslocamento e compressão de vísceras adjacentes e provocar sinais variados e inespecíficos, como dor abdominal, vômitos e diarreia (Prymak et al., 1988). Sintomas de alterações esplênicas incluem anorexia, perda de peso, aumento do volume abdominal, vômito, poliúria e polidipsia. No exame físico demonstra palidez das mucosas, petéquias e equimoses e aumento palpável do órgão (Neer, 1996).

\section{Relato de caso}

Paciente canino macho da raça Poodle com 8,8 $\mathrm{kg}$ consultado no Hospital Veterinário da UFPI, apresentando otite, foi verificado após ausculta sopro grau II. A partir do Ecocardiograma diagnosticou-se disfunção diastólica do ventrículo direito e disfunção da válvula mitral. No Raio-X verificou o aumento da silhueta cardíaca e dos átrios direito esquerdo. O baço pelo ultrassom estava com dimensões aumentadas, com bordas abauladas e com presença de múltiplos nódulos hipoecóicos por todo o parênquima. No perfil bioquímico sanguíneo apresentava-se com proteinúria. A esplenectomia foi indicada para evitar o avanço da doença e o tratamento da insuficiência cardíaca antes da cirurgia para 
estabilizar o paciente, este foi medicado com furosemida 1 comprimido de $17,6 \mathrm{mg}$ a cada $12 \mathrm{hs}$, pimobendan 2,2 $\mathrm{mg} /$ comprimido um comprimido às $12 \mathrm{~h}$ durante 14 dias, enalapril comprimido de 4,4 mg a cada 12 hs por 14 dias. Após os 14 dias a esplenectomia foi realizada, devido ao problema cardíaco foram utilizados poucos fármacos préanestésicos, utilizou-se tramadol $2 \mathrm{mg} / \mathrm{kg}$ e midazolam $0.4 \mathrm{mg} / \mathrm{kg}$. A indução anestésica foi feita com propofol $0,7 \mathrm{mg} / \mathrm{kg}$ e mantida com anestesia inalatória a base de Isoflurano que não causa alteração acentuada na função cardiovascular.

$\mathrm{O}$ acesso se deu por celiotomia mediana para adequada exposição do baço elevou-se de forma cuidadosa o baço, fez-se ligadura dupla da artéria esplênica (ligadura individual para evitar danos à artéria gastroepiploica) foi retirado o baço e inspecionado cada ligadura. Após a cirurgia retirou-se amostras para citológico, neste verificou-se a presença de histiocitose associado à hiperplasia linfoide com eritropoiese extramedular. No retorno pós-cirúrgico o animal apresentava ativo com bom estado de saúde, mantendo-se o tratamento para insuficiência cardíaca.
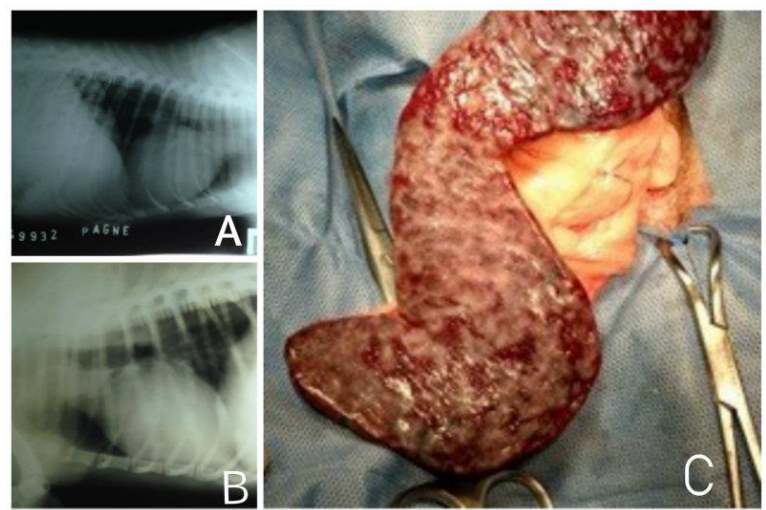

Figura 1. (A) e (B) Aumento da silhueta cardíaca, indicando aumento das câmaras cardíacas. (C) Nódulos esbranquiçados a cinza, devido a deposição hialina.

\section{Discussão}

O estimulo imune constante torna os folículos linfoides hiperplásicos e aumenta a proteína de fase aguda (Bergman \& Heidger, 2001). No caso relatado o paciente apresentava aumento de proteína sérica. $\mathrm{O}$ aumento de proteína sérica é um dos indicativos de inflamação generalizada (Salles et al., 1999, Brito, 2007).

Segundo Harrison (1990), o envelhecimento torna os cães susceptíveis a distúrbios circulatórios, imunológicos e neoplásicos. No presente relato o animal já tinha treze anos, embora a condição hormonal do paciente idoso favoreça alterações no baço a condição de inflamação generalizada sistêmica causada pela insuficiência cardíaca é provável que tenha contribuído de forma significante para formação nodular avançada por todo parênquima do baço.

De acordo com Torre-Amione (2005) a hiperextensão repetitiva dos cadiomiocitos gera a formação continua de citocinas pró-inflamatórias causando um estimulo imune constante e a resposta inflamatória local e sistêmica. O estimulo imune constante causa no baço o aumento de histiocitos e hiperplasia linfoide $\mathrm{e} a$ hiperexpressão dos centros germinativos. Com a progressão da doença e diminuição da resposta imune acontece a deposição hialina ocasionando a formação dos nódulos esbranquiçados a cinza presentes neste caso clínico (Bergman \& Heidger, 2001).

A esplenectomia é o tratamento indicado para alterações compressivas no baço. O acesso se dá por celiotomia mediana, elevar-se o baço doente do abdômen de forma gentil na manipulação para prevenir rupturas iatrogênicas. A esplenectomia se realizada com manutenção da artéria gastroepiplóica esquerda que é realizada pela ligadura individual dos vasos. Ligadura dupla da artéria esplênica e veia evitam hemorragias no pós-operatório, assim as ligaduras devem ser inspecionadas antes de fechar o abdômen. (Tobias \& Johnston, 2013).

\section{Conclusão}

Fatores como idade avançada, síndrome inflamatória sistêmica e doenças cardíacas favorecem o aumento da resposta imune e consequente alterações no baço. No presente relas clínico embora não se possa dimensionar a participação da síndrome inflamatória sistêmica na patogenia das alterações cardiovasculares e esplênicas, estas geram um estímulo imune e sintomas inflamatórios sistêmicos que é causa fundamental na progressão das patologias presente no paciente. A devida correlação permite aos clínicos possa diagnosticar em casos de patologias cardíacas alterações inflamatórias sistêmicas e alterações patológicas no baço.

\section{Referências Bibliográficas}

Bergman, R. \& Heidger, P. M. 2001. The complete spleen: structure, function, and clinical disorders. In: Bowdler, A. J. (ed.) The 
complete Spleen: Structure, Function, and Clinical Disorders. Springer Science \& Business Media, Totowa, NJ.

Brito, M. F. M. 2007. Síndrome da resposta inflamatória sistêmica\&58; denominação possivelmente aplicável a fenômenos dermatológicos Systemic inflammatory response syndrome \&58; a denomination possibly applied to dermatological phenomena. Anais Brasileiros de Dermatologia, 82, 359361.

Harrison, D. E. 1990. Genetic effort on aging Two. The Tellford Press Inc, New Jersey.

Mann, D. L. 2002. Inflammatory mediators and the failing heart: past, present, and the foreseeable future. Circulation Research, 91, 988-998.

Neer, T. M. 1996. Clinical approach to splenomegaly in dogs and cats. Compendium on Continuing Education for the Practicing Veterinarian, 18, 35-48.

Prymak, C., McKee, L. J., Goldschmidt, M. H. \& Glickman, L. T. 1988. Epidemiologic, clinical, pathologic, and prognostic characteristics of splenic hemangiosarcoma and splenic hematoma in dogs: 217 cases (1985). Journal of the American Veterinary Medical Association, 193, 706-712.

Salles, M. J. C., Sprovieri, S. R. S., Bedrikow, R., Pereira, A. C., Cardenuto, S. L., Azevedo, P. R. C., Silva, T. M. \& Golin, V. 1999. Síndrome da resposta inflamatória sistêmica/sepse 3/4 revisão e estudo da terminologia e fisiopatologia. Revista da Associação Médica Brasileira, 45, 86-92.

Tobias, K. M. \& Johnston, S. A. 2013. Veterinary Surgery: Small Animal-E-BOOK: 2-Volume Set. Elsevier Health Sciences, St. Louis, USA.

Torre-Amione, G. 2005. Immune activation in chronic heart failure. American Journal of Cardiology, 95, 3-8.

Torre-Amione, G., Kapadia, S., Lee, J., Durand, J.-B., Bies, R. D., Young, J. B. \& Mann, D. L. 1996. Tumor necrosis factor- $\alpha$ and tumor necrosis factor receptors in the failing human heart. Circulation, 93, 704-711.

Article History:

Received 13 November 2017

Accepted 18 January 2018

Available online 10 February 2018

License information: This is an open-access article distributed under the terms of the Creative Commons Attribution License 4.0, which permits unrestricted use, distribution, and reproduction in any medium, provided the original work is properly cited. 